

\title{
SHORT PULSED H2-F2 LASER FOR HYBRID LASER SYSTEMS
}

\author{
V. Igoshin, S. Pichugin
}

\section{To cite this version:}

V. Igoshin, S. Pichugin. SHORT PULSED H2-F2 LASER FOR HYBRID LASER SYSTEMS. Journal de Physique IV Proceedings, 1991, 01 (C7), pp.C7-625-C7-628. 10.1051/jp4:19917168 . jpa-00250845

\section{HAL Id: jpa-00250845 https://hal.science/jpa-00250845}

Submitted on 1 Jan 1991

HAL is a multi-disciplinary open access archive for the deposit and dissemination of scientific research documents, whether they are published or not. The documents may come from teaching and research institutions in France or abroad, or from public or private research centers.
L'archive ouverte pluridisciplinaire HAL, est destinée au dépôt et à la diffusion de documents scientifiques de niveau recherche, publiés ou non, émanant des établissements d'enseignement et de recherche français ou étrangers, des laboratoires publics ou privés. 


\section{SHORT PULSED $\mathrm{H}_{2}-\mathrm{F}_{2}$ LASER FOR HYBRID LASER SYSTEMS}

V.I. IGOSHIN and S.Yu. PICHUGIN

Samara Branch of P.N. Lebedev Physical Institute of USSR Academy of Sciences, Novo-Sadovaja str., Samara 443011, USSR

Abstract - The problem of oscillation, amplification and transformation into shortwave region of spectrum of a pulsed IR chemical hydrogen fluoride laser radiation a nanosecond time scale is considered. On the basis of computer calculations the conditions for obtaining the effective oscillation and amplification of HF chain reaction laser pulses with pulse length of the order of $10^{-8} \mathrm{~s}$ are revealed. It is offered to exite by this pulses the active medium of eximer lasers. The threshold intensity of IR radiation for $\mathrm{KrF}$ laser is found. The efficiency of IR $\rightarrow$ UV transformation of radiation is also calculated. The possibility of principle to create a pure chemical amplifier of short pulsed IR radiation, in wich the reaction is initiated by the optical discharge in the field of input signal, is shown.

\section{Introduction.}

Chemical laser based on the chain reaction between fluorine and hydrogen is one of the most powerful sources of IR laser radiation and it has high engineering efficiency [1]. It is of great interest to use this laser for obtaining soft $X$-ray or VUV coherent radiation with the pumping in a plasma created by pulsed IR radiation [2]. However, the pulse length of the existing HF lasers on the chain reaction is too high ( $\geq 100 \mathrm{~ns}$ ) for their application as a driver in hybrid laser system. Therefore, the search for conditions of oscillation and amplification of HF laser pulses with time duration of the order of $10^{-8} \mathrm{~s}$ and development of the methods of transformation of this radiation into shortwave region are of the present interest. 
2. Optimal mixture composition for short pulsed $\mathrm{HF}$ laser with e-beam initiation.

The most short duration of initiating the $\mathrm{H}_{2}+\mathrm{F}_{2}$ reaction can be achieved with the help of e-beam. The problem is to find mixture composition giving the best power parameters of a laser - specific volume energy and efficiency. This problem is solved by us on the basis of computer calculations with drowing the model of $\mathrm{H}_{2}-\mathrm{F}_{2}$ laser described in [1] and taking into account all principal processes: chemical rections, vibrational and rotational relaxation and induced emission. The essential moment is that our calculations are made for mixtures having longtime stability [1]. It may be done by introducing high enough quantity of oxygen. We obtained the dependence of specific energy $\varepsilon_{L}$ from mixture pressure $\varepsilon_{\mathrm{L}}\left(\mathrm{p}_{\mathrm{H}}+\mathrm{F}\right)$ for two compositions: $\mathrm{H}_{2}: F_{2}: O_{2}=1: 1: X$ and $H_{2}: F_{2}: O_{2}=1: 4: X$ and $f i x e d{ }^{2}$ level of initiation $n_{F}=$ $10^{18^{2} \mathrm{~cm}^{-3}}[1]$, where $X$ is equal to the value wich ensure mixture stability for a given pressure. The maximum value of $\varepsilon_{\mathrm{L}}=1.53 \mathrm{~kJ} / \mathrm{l}$ is achived for mixture $\mathrm{H}_{2}: \mathrm{F}_{2}: \mathrm{O}_{2}=600: 2400: 400$ torr. Pulse length is $t_{L_{3}} \simeq$ $20 \mathrm{~ns}$ and physical efficiency is $\eta_{\mathrm{Ph}} \simeq 220 \%$. To ensure $n_{\mathrm{F}}=10^{18} \mathrm{~cm}^{-3}$ for 20 ns one can need the beam current density as high as $j_{b} \simeq 10^{3}$ $\mathrm{A} / \mathrm{cm}^{2}$. This mixture can be used both in oscillator and amplifier.

\section{Chemical-eximer laser.}

The idea of chemical-eximer laser proposed here is to use short pulsed chemical IR laser ( $\mathrm{HF}$, DF $-\mathrm{CO}_{2}$ ) for exitation of oscillation in eximer laser. For analysis we have chosen $\mathrm{KrF}$ laser. The active medium consists from the mixture $\mathrm{F}_{2}-\mathrm{Kr}-\mathrm{He}$ and the main processes in the active mixture are well known [3]. We have written and numerically solved the rate equations for electron concentration, electron temperature and the concentrations of species (we take into account processes of exitation, ionization as well as elastic collisions). As a result the specific power of $\mathrm{KrF}$ laser radiation has been determined. The goals of calculation are that: determination of intensity of IR laser radiation wich is necessary for obtaining plasma parameters $\left(n_{e} \simeq 2 \cdot 10^{15} \mathrm{~cm}^{-3}, T_{e} \simeq 2 \mathrm{eV}\right.$ ) ensuering the effective operation of $\mathrm{KrF}$ laser; selective calculation of UV coherent radiation efficiency. We have analysed the mixture compositions wich are typical for experimental conditions: 1$) \mathrm{F}_{2}: \mathrm{Kr}: \mathrm{He}=1: 50: 375$ ( $p=1704$ torr), 2) $\mathrm{F}_{2}: \mathrm{Kr}: \mathrm{He}=1: 25$ : 
50 ( $p=1578$ torr $), 3) F_{2}: \mathrm{Kr}: \mathrm{He}=1: 21.4: 355$ ( $\mathrm{p}=2025$ torr). Exiting IR pulse had a maximum at $t=4 \mathrm{~ns}$, full duration 20 ns and duration at half maximum 10 ns. For all mixtures to achive the necessary values of $n_{e}$ and $T_{e}$ the mean intensity must be equal to $\simeq 10^{10} \mathrm{~W} / \mathrm{cm}^{2}$ in the case of $\mathrm{HF}$ laser $(\lambda=2.8 \mu \mathrm{m})$ and $\simeq 10^{9} \mathrm{~W} / \mathrm{cm}^{2}$ in the case of $\mathrm{CO}_{2}$ laser $(\lambda=10.6 \mu \mathrm{m})$. The initial electron concentration is equal to $n_{e}=10^{7}-$ $10^{9} \mathrm{~cm}^{-3}$ and it may be created by heating the small dispersed particles injected in the laser gas. The effective length of IR radiation absorption in the mixture 1 is equal $\simeq 50-130 \mathrm{~cm}(\lambda=10.6 \mu \mathrm{m})$ and 600 $1900 \mathrm{~cm}(\lambda=2.8 \mu \mathrm{m})$. The oscillation efficiency of $\mathrm{UV}$ radiation in respect to absorbed energy is about $10 \%$ for mixture $1\left(\varepsilon_{L}-5 \mathrm{~J} / 1\right)$ and $5 \%$ for mixture $2\left(\varepsilon_{\mathrm{L}} \simeq 1 \mathrm{~J} / 1\right)$. Note that quantum efficiency of $\mathrm{KrF} \mathrm{la-}$ ser may be determined as $\eta=h \nu / E_{\mathrm{Kr}} * 0.5$, where $h \nu \approx 5 \mathrm{eV}, \mathrm{E}_{\mathrm{Kr}} * 9.9 \mathrm{eV}$ is the $\mathrm{Kr}$ exitation energy. If the efficiency of chemical laser is equal to $200 \%$ then we may expect that the efficiency of chemical-eximer laser emitting in UV region of spectrumwill be the range $20-100 \%$.

4. Short pulsed $\mathrm{H}_{2}-\mathrm{F}_{2}$ amplifier initiated by optical discharge.

As it is well known, pulsed chemical lasers can be initiated by electrical discharge. The active centers of chain reaction are formated in the number of processes the most essential of wich are dissotiative attachment of electrons to $F_{2}$ molecules and dissotiation of $F_{2}$ and $\mathrm{H}_{2}$ molecules by electron impact. One can expect the possibility of realization of these processes under the conditions of developing optical discharge in chemical lasers media, when electrons increase their concentration in IR laser field. In this case it showld be possible to initiate the amplifier by the help of input laser radiation and develop the pure chemical amplifier not consuming during its operation the energy of e-beam, electrical discharge or UV radiation. Let us consider the medium of hydrogen fluoride amplifier $\mathrm{H}_{2}-\mathrm{F}_{2}-\mathrm{O}_{2}-\mathrm{He}$ under the action of laser radiation with peak intensity of the order $10^{11} \mathrm{~W} / \mathrm{cm}^{2}$. At this intensity the developing of electron avalanche is possible. The initial electrons will arise due to evaporation of ultradispersed particles presenting in laser gase. Radius of these particles is $0.01-0.1 \mathrm{\mu m}$ and their concentration is about $10^{7} \mathrm{~cm}^{-3}$. The evaporation time of particles is less then 1 ns and during the evaporation the formation of thermoelectrons takes place. The electrons quickly increase their energy in IR laser field and cause 
the ionization of atoms and molecules with formation of new electrons. Diffusion coefficient of electrons with the energy $\sim 3 \mathrm{eV}$ is equal to $10^{3} \mathrm{~cm}^{2} / \mathrm{s}$, so the time of electron mixing is about 1 ns. It gives us the principal possibility of developing pure chemical HF amplifiers of nanosecond time scale. The formation of free atoms is due to different processes (e.g. $F_{2}+e \rightarrow 2 F+e$ ). So, under the proper intensity of input radiation the front of the pulse results to initiation of amplifier and other parts of pulse will be intensifie d. To calculate performances of such amplifier the computer analysis based on the equivalent two level model of $\mathrm{H}_{2}-\mathrm{F}_{2}$-laser discreibed in [1] is used. In addition we take into account the processes of electron collision with atoms, molecules and ions, such as $F_{2}+e \rightarrow$ $\mathrm{F}^{-}+\mathrm{F}, \mathrm{F}^{-}+\mathrm{e} \rightarrow \mathrm{F}+\mathrm{Ze}, \mathrm{F}_{2}+\mathrm{e} \rightarrow 2 \mathrm{~F}+\mathrm{e}, \mathrm{H}_{2}+\mathrm{e} \rightarrow 2 \mathrm{H}+\mathrm{e}, \mathrm{F}_{2}+e$ $\rightarrow \mathrm{F}_{2}^{+}+2 e, \mathrm{~F}_{2}^{+}+\mathrm{e} \rightarrow 2 \mathrm{~F}, \mathrm{~F}_{2}^{+}+\mathrm{F}^{-} \rightarrow 3 \mathrm{~F}$ and others. The variation of intensity of laser radiation along $x$-axis is described by radiation transfer equation

$$
\frac{1}{\mathrm{c}} \frac{\partial \mathrm{I}}{\partial \mathrm{t}}+\frac{\partial \mathrm{I}}{\partial \mathrm{x}}=\mathrm{P}_{\mathrm{L}}-\mu \mathrm{I}
$$

where $P_{L}$ is the specific power of $H_{2}-F_{2}$ amplifier and $\mu$ is the absorption coefficient of laser radiation due to presence of electrons. The calculations were made for $\mathrm{H}_{2}-\mathrm{F}_{2}-\mathrm{He}$ mixtures with total pressure from 0.3 to $2.8 \mathrm{MPa}$. For the mixture $\mathrm{H}_{2}: \mathrm{F}_{2}: \mathrm{He}=1: 1: 1.5(\mathrm{p}=2.8 \mathrm{MPa})$ stabilized by oxygen the ratio of output to input $(320 \mathrm{~J} / 1)$ laser energy is equal to 6 . For the mixture $\mathrm{H}_{2}: \mathrm{F}_{2}: \mathrm{He}=1: 1: 4 \quad(\mathrm{p}=1.6 \mathrm{MPa})$ this ratio is equal to 2 . Input pulse has the maximum intensity $\simeq 2 \cdot 10^{11}$ $\mathrm{W} / \mathrm{cm}^{2}$ and duration $15 \mathrm{~ns}$. Effective length of absorption is about 10 $\mathrm{m}$. So, the realization of proposed mechanism of amplification is possible under the conditions of longitudinal scheme of exitation in longdistance narrow channels.

References.

1. N. G. Basov, A. S. Bashkin, V. I. Igoshin, A. N. Oraevsky, V. A. Shcheglov. Chemical Lasers. Springer-Verlag, 1990.

2. Proc. SPIE Vol. 875 Short and Ultrashort Wavelength Lasers. 1988.

3. V. Yu. Baranov, V. M. Borisov, Yu. Yu. Stepanov. Electrorasr jadnye eksimernye lasery na galogenidach inertnych gasov. Energoatomizdat, 1988 (in Russian). 